\title{
JEKK
}

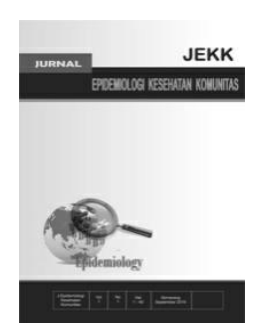

\section{Prevalence of Genu Valgum in Children Aged 10-12 Years with Excessive Body Weight (Overweight/Obesity) in Sanur Kaja Village, Denpasar}

\author{
Vidya Rahmayunissa Swandi Putri", Ni Wayan Tianing ${ }^{* *}$, Agung Wiwiek Indrayani****, Ari \\ Wibawa $^{* * * *}$, Sayu Aryantari Putri Thanaya ${ }^{* * * *}$ \\ *Bachelor of Physiotherapy and Physiotherapy Profession Study Program, Faculty of Medicine, \\ Udayana University, **Biochemistry Department, Faculty of Medicine, Udayana University, \\ ****Pharmacology Departement, Faculty of Medicine, Udayana University, ${ }^{* * * *}$ Physiotherapy \\ Department, Faculty of Medicine, Udayana University
}

\begin{abstract}
Background: Overweight/obesity is a global health problem, both in developed and developing countries and the number of overweight/obese people increases every year. Being overweight during childhood increases the risk of obesity in adulthood and can lead to musculoskeletal disorders, one of which is genu valgum. The purpose of this study was to determine the prevalence of genu valgum in children aged 10-12 years who are overweight/obese in Sanur Kaja Village, Denpasar.

Methods: This study was an observational study with a cross-sectional design conducted at elementary schools in Sanur Kaja Village in April 2019. The sampling technique used was purposive sampling. A total of 78 children were included in this study. The univariate analysis in this study was genu valgum, overweight/obesity, age, and gender.

Result: The prevalence of genu valgum in children aged 10-12 years in Sanur Kaja Village was $46.7 \%$ in overweight children and $53.3 \%$ in obese children, with 30 people $(38.5 \%)$ experiencing genu valgum out of the total sample of 78 people $(100 \%)$.

Conclusion: Based on the result of this study, the incidence of genu valgum was higher in children aged 10-12 years who were obese compared to children with overweight body mass index. It is recommended that children who are obese and overweight to control their eating patterns, maintain normal body weight, and do enough physical activity.
\end{abstract}

Keywords: Overweight; obesity; genu valgum; prevalence

*Coresponding author, agungwiwiekfk@gmail.com 


\section{Introduction}

Overweight and obesity are world health problems in both developed and developing countries, and the number of people who are overweight and obese is increasing every year. ${ }^{1}$ Based on data from the World Health Organization (WHO) in 2010, around 43 million children are overweight, and nearly 35 million of them are living in developing countries. The remaining 8 million children are in developed countries. $^{2}$ Data from Riskesdas in 2010 shows that the prevalence of overweight and obesity in children aged 6-12 years was 9.2\%, which increased in 2013 to $18.8 \%$ in children aged 512 years. $^{3}$

Overweight and obesity during childhood increases the risk of obesity in adulthood and can potentially lead to metabolic and degenerative diseases in the future. In addition, overweight and obesity in childhood can trigger future health problems such as an increased risk of fractures, more frequent back pain, hip pain and knee pain, changes in foot structure (genu valgum), and osteoarthritis. ${ }^{4}$

In this study, the researcher chose Sanur Kaja Village as the study location because there are three elementary schools in Sanur Kaja Village, namely SDN 2 Sanur, SDN 6 Sanur, and SDN 12 Sanur, according to data on the official website of Denpasar City Government. ${ }^{5}$ There are several shopping centers and places to sell food, including fast food such as $K F C$ and Dunkin Donuts, which are much favored by children. The existence of these fast food restaurants is one of the factors that can increase the risk of overweight and obesity in children, which can trigger various diseases and abnormalities in the body, one of which is genu valgum.

The result of a study by Szymanska et al. ${ }^{6}$ shows that children who are overweight and obese are more at risk of experiencing genu valgum. ${ }^{6}$ This is consistent with the result of a study by Ciaccia et al. ${ }^{7}$; the risk of genu valgum in overweight primary school-aged children is 6.0 to 75.7 times greater than primary schoolaged children who have normal body weight or underweight. $^{7}$

Genu valgum is a common orthopedic condition in children that is characterized by medial angulation of the knee joint and lateral deviation of the femur and tibia on the longitudinal axis so that the mechanical axis shifts laterally and causes pathological stress on the femur and lateral tibia, which triggers pain. ${ }^{8}$ Genu valgum is said to be pathological if it occurs above the age of 8 years and results in a tibiofemoral angle (TFA) of more than $15^{\circ}$ and an intermalleolar distance of greater than or equal to $8 \mathrm{~cm} .{ }^{9}$

Genu valgum can occur due to other etiologies such as knee injuries, overweight and obesity, vitamin deficiency, laxity of the ligaments around the knee joint, and developmental problems. Therefore, children with genu valgum usually feel discomfort and have some functional impairments such as postural instability, impaired walking/gait patterns, and difficulty in standing, walking, running, and going up and down the stairs. ${ }^{10}$

As overweight and obese children are at risk of experiencing genu valgum, it is important to know the prevalence of genu valgum in children aged 10-12 years who are overweight and obese in Sanur Kaja Village, Denpasar. Therefore, this study aimed to determine the prevalence of genu valgum in children 10-12 years who are overweight and obese in Sanur Kaja Village, Denpasar to increase the level of understanding and awareness of parents and children regarding how overweight and obesity can have an impact on the incidence of genu valgum.

\section{Methods}

This study was an observational study with a cross-sectional design that was conducted at three elementary schools in Sanur Kaja Village, namely SDN 2 Sanur, SDN 6 Sanur, and SDN 12 Sanur in April 2019. The samples in this study were children aged 10-12 years who attended these three elementary schools.

The inclusion criteria of this study were as follow: aged 10-12 years, had a Body Mass Index (BMI) in the category of overweight and obesity, i.e. in boys ranging from 18.5 to $>23.5$ and girls ranging from 19.0 to $>25.0$, and willing to become a sample of this study from the beginning until the end by receiving permission from parents/guardians through signing the informed consent. 
The exclusion criteria in this study included the existence of other conditions or diseases that can interfere with the measurement, such as bone infection (osteomyelitis) and rickets, past injuries to the bones that can affect the shape of the foot, and the resignation of the sample from the study for certain reasons.

The sampling technique used was nonrandom sampling, namely purposive sampling. The minimum sample size required was 42 samples. In this study, the total number of samples obtained was 78 children with a BMI of overweight and obesity who fulfilled the inclusion and exclusion criteria.

Data analysis in the form of univariate analysis was performed using SPSS. The data analyzed were genu valgum, overweight/obesity, age, and gender.

This study has obtained ethical permission from the Health Research Ethics Commission of the Faculty of Medicine, Udayana University and Sanglah General Hospital, Denpasar. Additionally, to maintain the samples' confidentiality, data collection did not include the respondents' identities but involved the use of codes.

\section{Result}

Table 1. Distribution of Frequency based on Age, Gender, and BMI

\begin{tabular}{lcc}
\hline Variable & $\begin{array}{c}\text { Frequency } \\
(\mathrm{n})\end{array}$ & $\begin{array}{c}\text { Percentage } \\
(\%)\end{array}$ \\
\hline Aged (year) & & \\
10 & 29 & $37.2 \%$ \\
11 & 26 & $33.3 \%$ \\
12 & 23 & $29.5 \%$ \\
\hline Gender & & \\
Male & 33 & $42.3 \%$ \\
Female & 45 & $57.7 \%$ \\
\hline BMI & & \\
Overweight & 45 & $57.7 \%$ \\
Obesity & 33 & $42.3 \%$ \\
\hline Prevalence of & & \\
Genu valgum & & \\
Yes & 30 & $38.5 \%$ \\
No & 48 & $61.5 \%$ \\
\hline
\end{tabular}

Table 2. Prevalence of Genu valgum based on BMI (Overweight dan Obesity)

\begin{tabular}{cccc}
\hline $\begin{array}{l}\text { Body Mass } \\
\text { Index }\end{array}$ & \multicolumn{2}{c}{ Prevalence of } & \\
& \multicolumn{2}{c}{ Genu valgum } & Total \\
\cline { 2 - 3 } & Yes & No & \\
\hline Overweight & 14 & 31 & 45 \\
& $(46.7 \%)$ & $(64.5 \%)$ & $(57.7 \%)$ \\
Obesity & 16 & 17 & 33 \\
& $(53.3 \%)$ & $(35.5 \%)$ & $(42.3 \%)$ \\
\hline Total & 30 & 48 & 78 \\
& $(100 \%)$ & $(100 \%)$ & $(100 \%)$ \\
\hline
\end{tabular}

\section{Discussion}

The results showed that most participants were aged $10(37.2 \%)$. Based on gender, the number of female participants was greater than males, with 45 people $(57.7 \%)$ and 33 people (42.3\%), respectively. Based on BMI, from 78 participants, 45 people or $57.7 \%$ were overweight, and 33 people or $42.3 \%$ were obese.

From 78 participants, there were 30 people (38.5\%) who experienced genu valgum, while 48 people $(61.5 \%)$ did not. The reason for this can be because the occurrence of genu valgum is also influenced by physical activity; as stated by Weghuber and O'Malley, ${ }^{11}$ excessive body weight alone is not a condition that can lead to pathological conditions because the bones can adapt, in particular, bone architecture can develop in response to the dynamic pulling of muscles and mechanical impact. Thus, children who are classified as obese but are physically active will have a better bone development (bone growth can adjust to the load obtained) compared to children who are classified as obese but are not active. ${ }^{11}$

The three elementary schools where this study was conducted routinely carry out community services and various physical activities on Saturdays for students who are interested, such as yoga, basketball, football, badminton, and gymnastics.

In this study, the prevalence of genu valgum is higher in the obese body mass index compared to the overweight body mass index. Based on the total prevalence of genu valgum, 30 people from the total sample of 78 people (100\%) experienced genu valgum. From the 30 people, 14 people or $46.7 \%$ were categorized as overweight, while 16 people or $53.3 \%$ were in 
the obese category. This is consistent with the findings of a study by Shohat et al., ${ }^{12}$ which reported that the highest prevalence of genu valgum was in subjects with obesity (28.8\%), followed by overweight subjects $(17.7 \%)$ and subjects with normal weight $(3.4 \%)$, while the lowest prevalence of genu valgum was found in underweight subjects $(1.5 \%) .^{12}$

Obesity causes an excessive mechanical burden on the locomotor and misalignment of posture towards the center of mass (CoM), thereby causing functional changes in the lower limbs and increasing in the body's mechanical need to adapt to new physical conditions. ${ }^{13}$ This can occur because of the excessive body weight in children, which places greater compression of the lateral distal femoral physis (HeuterVolkman's Law) and causes microtrauma to recur on the femoral distal physis, where it leads to reduced lateral growth so that it progressively becomes valgus deformity. ${ }^{14}$ Ferber et al. ${ }^{15}$ states that this occurs because children who are overweight will experience muscle imbalance or imbalance in leg muscle strength from holding excess body weight due to fat deposits under the subcutaneous. ${ }^{15}$

Muscle imbalance occurs between $M$. Vastus Lateralis (VL) that pulls the patella upward and outward (lateral), and M. Vastus Medialis Oblique (VMO), which is the only quadriceps muscle that pulls the kneecap upward and slightly inward (medial) so that the patella can be in its proper position (the degree of valgus from tibiofemoral in men is $7 \circ$ and $8^{\circ}$ in women). ${ }^{7}$ In the condition of genu valgum, tightness/stiffness in the Lateral Retinaculum, VL, and ITB also occurs, which will encourage the shell the knee to shift sideways, especially if the VMO is weak. This is followed by weakness in M. Gluteus Medius, where poor buttock muscle control allows the knee to go in medially and move laterally relative to the patella, resulting in medial angulation of the knee joint and lateral deviation of the femur and tibia on the longitudinal axis, so the mechanical axis shifts laterally and an increase in tibiofemoral angle causes pathological stress on the femur and tibia or known as patellofemoral pain. ${ }^{15}$

Similarly, Shohat et al. ${ }^{12}$ also states that genu valgum can cause musculoskeletal dysfunction including abnormal joint loading and muscle imbalance, which will have an impact on patellofemoral pain. ${ }^{12}$

\section{Conclusion}

Based on the results of the present study, the prevalence of genu valgum in children aged 10-12 years with excessive body weight (overweight/obesity) in Sanur Kaja Village is $46.7 \%$ in overweight children and $53.3 \%$ in obese children, with 30 people experiencing genu valgum $(38.5 \%)$ out of the total sample of 78 people $(100 \%)$.

It is hoped that this study can be used as an educational and evaluation material to maintain the shape of the foot to remain stable. It is recommended that participants maintain a normal knee angle (TFA) by maintaining an ideal BMI and carrying out appropriate physical activity. Management for someone who has genu valgum can be in the form of exercises such as wall squats with a ball in order to reduce the angle (TFA) formed by genu valgum. Moreover, one can consult a doctor or physiotherapist to get appropriate treatment to prevent permanent deformity.

\section{Acknowledgement}

The author would like to thank the study participants who have given permission and were willing to be the research subject and contribute to data collection and to all parties involved in the process of preparing this manuscript.

\section{References}

1. Anindyawati, D. D. 2016. Hubungan Konsumsi Fast Food, Aktivitas Fisik, dan Tingkat Pendidikan Orang Tua dengan Kejadian Gizi Lebih pada Anak SD. Fakultas Kesehatan Masyarakat Universitas Muhammadiyah Semarang.

2. World Health Organization. 2010. Growth Reference 6-19 years. Available at: http://www.who.int [Accessed 25 September 2018]. 
3. Riset Kesehatan Dasar (RISKESDAS). 2010. Riskesdas Nasional. Available at: http://kesga.kemkes.go.id/images/pedoman /Riskesdas\%202010\%20Nasional.pdf [Accessed 17 September 2018].

4. Landauer, F., Huber, G., Paulmichl, K., O’Malley, G., Manggey, H., \& Weghuber, D. 2013. Timely Diagnosis of Malalignment of the Distal Extremities Is Crucial in Morbidly Obese Juveniles. The European Journal of Obesity, 542-551.

5. Situs Resmi Pemerintah Kota Denpasar. 2013. Desa Sanur Kaja. Available at: https://www.denpasarkota.go.id/ [Accessed 20 September 2018].

6. Szymanska, A. J., \& Mikolajczyk, E. 2016. Genu valgum and Flat Feet in Children With Healthy and Excessive Body Weight. Pediatric of the American Physical Therapy Association, 33-100.

7. Ciaccia, M. C., Pinto, C. N., Golfieri, F. d., Machado, T. F., Lozano, L. L., Silva, J. M., et al. 2017. Prevalence of Genu valgum in Public Elementary Schools in the City of Santos (SP), Brazil.

8. Rahardja, F. B. 2012. Genu varum dan valgum. Fakultas Kedokteran Universitas Pelita Harapan.

9. Yeo, A. J. 2015. Normal Lower Limbs Variant in Children. The Royal London \& Barth and The London Children's Hospitals, Barth Health NHS Trust, London, 351;h3394.
10. Ganesan, B., Fong, K., Luximon, A., \& AlJumaily, A. 2016. Kinetic and kinematic analysis of gait pattern of 13 year old children with unilateral genu valgum. European Review for Medical and Pharmacological Sciences, 3168-3171.

11. Weghuber, Daniel., \& O'Malley, Grace. 2015. Orthopaedic Complications. European Childhood Obesity Group.

12. Shohat, N., Machluf, Y., Farkash, R., Finestone, A. S., \& Chaiter, Y. 2018. Clinical Alignment among Adolescents and Association with Body Mass Index: A Large Prevalent Study.

13. Souza, A. A., Ferrari, G. L., Junior, J. P., Silva, L. J., Oliveira, L. C., \& Matsudo, V. K. 2013. Association between knee alignment, body mass index, and physical fitness variables among students: a cross sectional study. Elsevier, 46-51.

14. Tabaku, S. B., Shults, J., Zemel, B. S., Leonard, M. B., Berkowitz, R. I., Stettler, N., et al. 2014. Obesity Is Associated with Greater Valgus Knee Alignment in Pubertal Children, and Higher Body Mass Index Is Associated with Greater Variability in Knee Alignment in Girls. The Journal of Rheumatology.

15. Ferber, R., Kendall, K. D., \& Farr, L. 2011. Changes in Knee Biomechanics After a Hip-Abductor Strengthening Protocol for Runners With Patellofemoral Pain Syndrome. Journal of Athletic Training, 142-149. 